\title{
Teatro e Autonomia: uma proposta a/r/tográfica metodológica.
}

\author{
Almando José Storck Junior¹; Dr. Sandro Martins Costa Mendes². \\ ${ }^{1}$ storck_psi22@ hotmail.com, Universidade Federal do Pampa; ${ }^{2}$ sandromcm@gmail.com, \\ Universidade Federal do Pampa.
}

"O Teatro é a arte do Ator!"

Etienne Decroux

\begin{abstract}
Resumo
O presente artigo vem propor, a partir de uma experiência prática nas artes cênicas, a criação de uma metodologia, para uma vivencia artístico-educacional de aprimoramento das técnicas pessoais de comunicação, troca de experiências pessoais e coletivas. Essa metodologia baseia-se nas técnicas de trabalho ator, do teatro do oprimido, de textos contemporâneos e uso do conceito de Empowerment como proposta de fortalecimento da autonomia individual e coletiva. Sabendo que metodologia científica cuida dos procedimentos, ferramentas e caminhos do fazer científico, e que o indivíduo é, também, um ser político, propõe-se, a partir da Investigação Baseada em Arte (IBA), uma pesquisa a/r/tográfica para uma compreensão estendida do fazer universidade e uma ampliação do poder de autonomia. Como resultado, a reflexão sobre as técnicas direcionadas ao teatro, apontadas anteriormente, aliadas a preocupações acerca de desinibição e expressão oral e corporal de acadêmicos e profissionais interessados possibilitou a criação da metodologia pretendida. Desta forma, o trabalho de investigação teórica conclui-se, deixando a possibilidade de transformar-se em projeto de extensão.
\end{abstract}

Palavras chaves: a/r/tografia, empowerment, metodologia cientifica; teatro contemporâneo.

\begin{abstract}
This article proposes, from a practical experience in the performing arts, the creation of a methodology for an artistic and educational experiences enhancement of personal communication skills, exchange of personal and collective experiences. This methodology is based on the actor working techniques, the theater of the oppressed, of contemporary texts and use of the concept of empowerment as proposed strengthening of individual and collective autonomy. Knowing that scientific methodology takes care of procedures, tools and ways of doing science, and that the individual is also a political being, it's proposed from the Arts-based Research (ABR), a search to a/r/tographyc to an extended understanding of the university and to an expansion of the power of autonomy. As a result, the reflection on the techniques directed to the theater, set out above, combined with concerns about disinhibition and oral expression and body of academics and professionals interested enabled the creation of the proposed methodology. Thus, the theoretical research work is concluded, leaving the possibility of becoming an extension project.
\end{abstract}

Keywords: a/r/tography, empowerment, scientific methodology, contemporany theatre.

\section{Apresentação}

Sabe-se que a instituição de ensino superior é um ambiente onde se deve provocar a incitação das ideias, onde os saberes empíricos e dogmáticos são postos a prova de um corpo coletivo dotado de vontades. Os anseios de um ingressante vão desde a gana teórico-prática do conteúdo estudado até uma boa oralidade a sua gestualidade causal. 
Após a quebra da quarta parede ${ }^{1}$ proposta pelo teatro contemporâneo, o teatro chegou ao seu público de forma direta, possibilitando novas formas de se fazer-ver-sentir teatro. Desde então vem se buscando integrar o teatro a diversas formas de se produzir ideias, dentro e fora dos muros das instituições de ensino, seja ele como expressão artística, como manifestação política ou até mesmo como uma filosofia prática.

Usando deste teatro de possibilidades e partindo do principio de que o aluno tem desejos de melhorar sua expressividade (oral e gestual) em sala de aula, e fora dela, a oficina vem propor uma vivência prática de construção de ideias, ações corporais do teatro voltadas para o âmbito acadêmico e, uma possível, [re]descoberta do vivenciar uma instituição de ensino superior, não apenas instalar o espirito acadêmico, mas fazer com que o alunoparticipante seja parte do corpo pensante ativo da universidade.

Observei durante os anos de trabalho dentro de uma autarquia do Sistema $\mathrm{S}^{2}$, no munícipio de Macapá/AP, uma forte tendência dos participantes das oficinas de teatro, as quais ministrei como instrutor dentro da instituição, a um crescimento automático da capacidade de autoconhecimento e autogoverno diante das adversidades vindouras, através de relatos dados em finais das seções diárias das aulas, como parte do processo de ensino, assimilação de conteúdo e ampliação das perspectivas de trabalho e interpretação, isso de forma indiretamente induzida, mas significantemente percebida, me fazendo refletir o tipo de conhecimento transmitido e como aquele conhecimento refletia na vida pessoal dos participantes.

Fazendo uso dessas reflexões, pesquisei e fiz uso de materiais teóricos e práticos, do teatro contemporâneo para aprofundar e exercer com mais competência e eficiência os ensinamentos teatrais para além do uso artístico de sua funcionalidade, transpondo suas regras e fazeres para uma realidade, possivelmente, alheia a sua cátedra mor. O presente artigo surgiu na tentativa de sanar a necessidade de alunos e demais interessados em busca de uma melhor expressividade da oralidade, desinibição diante do público/plateia e desempenho de raciocínio lógico em apresentações acadêmicas, ou não, dentro e fora da instituição.

Entre os discentes, em modo geral, tem se uma cultura pobre de não buscar o desenvolvimento das competências acadêmicas, desde a teoria até a prática. Instalou-se o ideal comodista de obtenção de notas sem o conhecimento de fato do assunto, reforçando um

\footnotetext{
${ }^{1}$ Linha imaginária colocada à altura da boca de cena, e que teoricamente separa o/a ator/atriz da plateia, protegendo-o/a e deixando-o/a isolado do público.

${ }^{2} \mathrm{O}$ sistema $\mathrm{S}$ é formado por organizações e instituições referentes ao setor produtivo, tais como indústrias, comércio, agricultura, transporte e cooperativas que tem como objetivo, melhorar e promover o bem estar de seus funcionários, na saúde e no lazer, por exemplo, como também a disponibilizar uma boa educação profissional.
} 
analfabetismo funcional provido da perversa aplicação pedagógica das disciplinas básicas, oriundas dos ensinos fundamental e médio. As instituições de ensino superior no Brasil vêm formando repetidores, como sugere o pensador Pedro Demo (2002), originando indivíduos sem autonomia de pensar sua realidade, seu papel na instituição e sua situação enquanto sujeito formador de ideias no contexto social. A falta de capacitação na oralidade, desinibição e raciocínio lógico entre docentes e discentes das universidades, dificulta a transmissão de conhecimento, deixando a vista grossa as possíveis respostas desejadas. Tem-se a imagem do docente como um destino a se chegar, um "porto" de saberes e conhecimento, sempre na expectativa do melhor. Mas docente não pode, e não deve, ser encarado como um semideus portador de todo conhecimento, mas como um meio a se chegar. Docente é ponte, é caminho, é meio por onde se canaliza e segmenta conhecimento, não se encerra o conhecimento em si, mas através de, se faz.

Com a perspectiva indigência de desenvolvimento da oralidade e desinibição das partes interessadas, a vivência artística-educacional propõe um olhar mais crítico e objetivo do indivíduo e seu cotidiano, e as praticas educacionais. Uma reflexão teórico-prática sobre o uso das linguagens cênicas contemporâneas como instrumento de autonomia dos colaboradores e desenvolvimento das competências acadêmicas.

\section{Teatro contemporâneo como metodologia}

O teatro é comumente usado para interpretar ou representar uma mensagem a qual se busca uma compreensão dinâmica e prática de algum interesse teórico, como nos sugere Burnier 2009 interpretar quer dizer traduzir, e representar significa "estar no lugar de" (o chefe de gabinete que representa o prefeito), mas também pode significar o encontro de um equivalente. [...] "Equivalente" é "ter o mesmo valor sendo, mesmo assim, diferente" (p. 21). Logo, todo intérprete é um intermediário, alguém que está entre. Encontrar o equivalente entre o que se estuda/pesquisa e o que se transmite é sempre uma tarefa árdua, porém louvável.

A prática teatral ainda é vista como um artificio lúdico-pedagógico nas esferas educacionais, principalmente nos ensinos fundamental e médio, onde a equação “Texto +Decorar + Marcação=Teatro" é usada de forma corriqueira como processo de ensino aprendizagem, e sem nenhum preparo prévio daquele que deveria transmitir conhecimento. É preciso um olhar mais atento à prática teatral. No mundo contemporâneo aperfeiçoaram-se as técnicas já estabelecidas e surgiram outras mais estruturadas e com foco naquilo que deve ser o principal elemento do teatro: o ator. O ator - é ele mesmo, obra de arte viva. Por isso a 
necessidade, cada vez maior, em trabalhar o seu instrumento artístico, ou seja, seu corpo, sua voz, seus afetos, suas relações, seu conhecimento, sua criatividade e sensibilidade. Os pioneiros da dramaturgia centrada no ator, como François Delsarte, Emile Jaques-Dalcroze, Jacques Coupeau dentre outros, deixaram bases satisfatórias para o surgimento de técnicas de dramatização e composição cênica.

Dentre as principais características do teatro contemporâneo, como por exemplo a comunicação teatral passando pelos sentidos e sem apelação para a mente racional, Meyerhold (1922) abre espaço para o teatro interativo, por acreditar que o ator não deve ficar escravo do texto, propondo em algumas montagens, a circulação de atores na plateia e do público em cena. Além destas, outras características se destacam, como a estética Absurda ${ }^{3}$ onde retrata a condição humana incompreensível e sem perspectiva (a ideia é fugir da estrutura narrativa familiar e sequencial, para abordar temas mais sombrios como os conflitos nas relações interpessoais, o isolamento humano, e o caminhar inevitável para a morte); o Teatro Pobre de Jerzy Grotowski, onde se propõe uma encenação de extrema economia de recursos cênicos (cenográficos, indumentários, etc.), buscando trabalhar apenas com o que é extremamente essencial à cena, deixando somente a relação entre o ator e o espectador.

Ao apresentar suas ideias para uma plateia, tem se a ideia de que está representando um equivalente de um montante pesquisado e posto a prova da subjetividade alheia.

\footnotetext{
Quando um indivíduo desempenha um papel, implicitamente solicita de seus observadores que levem a sério a impressão sustentada perante eles. Pede-lhes para acreditarem que o personagem que veem no momento possui atributos que aparenta possuir, que o papel que representa terá as consequências implicitamente pretendida por ele e que, de um modo geral, as coisas são o que parecem ser (GOFFMAN, 1985. p. 25),
}

sendo assim assumimos personas que representam papeis no cotidiano, e cada qual, com sua intencionalidade, causa uma reação em "plateias" diferentes, exigindo destas uma atenção especial em cada situação onde sua persona está presente.

Uma das inquietações mais visíveis hoje no meio acadêmico é o escasso uso da subjetividade entre os discentes. Comungo da ideia de Demo (2002, p.84) onde todos os cursos, antes de pretenderem oferecer especialização profissional, deveriam trabalhar com o aluno as bases do saber pensar, incluindo fazer ciência. Somos conduzidos em rumo à repetição, e não a criação de novos paradigmas do uso, e aprimoramento, da subjetividade enquanto produtor de ciência. Todo processo de construção do saber deve ser encarado de

\footnotetext{
${ }^{3}$ ESSLIN, Martin. O Teatro do Absurdo. $3^{\text {a }}$ Reimpressão. Rio de Janeiro. Zahar Editores, 1968.
} 
forma a integrar o máximo de informação possível sobre o que se quer expressar, peneirado por um filtro de referências do próprio pesquisador, e união colaborativa daqueles que, possivelmente, irão nortear suas ideias e pesquisa.

Trabalhando com uma expectativa de continuidade e fortalecimento da prática acadêmica e do fortalecimento do poder de autonomia, através de técnicas teatrais contemporâneas, estabelece uma nova probabilidade de cogitar métodos dinâmicos de ensinoaprendizagem e empoderamento. Um exemplo bastante prático dessa perspectiva é o uso do Método Viewpoints ${ }^{4}$ como ferramenta nesse aporte metodológico,

Training forges relationships, develops skill and provides an opportunity for continued growth. Viewpoints training and Composition work allow actors and their collaborators to practice creating fiction together' on a daily basis using the tools of time and space. This daily practice keeps the artistic juices flowing, creates cohesive ensembles and allows individuals and groups to practice speaking the language of the $\operatorname{stag}^{5}$ (BOGART et all, 2005, p. 17).

Vivenciar na prática uma experiência de criatividade física e mental expande as possibilidades do sujeito autônomo e acadêmico.

A metodologia científica não se restringe às normas acadêmicas de redação e produção de textos, está além de pesquisar, refletir e posicionar argumentos, metodologia é uma preocupação instrumental. "Trata das formas de se fazer ciência. Cuida dos procedimentos, das ferramentas, dos caminhos. A finalidade da ciência é tratar a realidade teórica e praticamente" (DEMO, 1985. p. 19), então a oralidade também é uma preocupação instrumental e prática da metodologia cientifica, pois trata da externalização oral da coleta dos dados e transformação dos elementos em informação significativa na defesa dos argumentos.

A experiência de uma vivência de perspectiva teatral pode transformar a permissividade de si mesmo em uma experiência mais larga e prazerosa. Trabalhando de forma mais condensada e objetiva, é capaz de se chegar a um resultado significativo/palpável a curto e médio prazo para com aqueles dispostos a experenciar uma vivencia coletiva em teatro contemporâneo.

\footnotetext{
4 “... processo aberto, e não uma técnica rigidamente formatada, constituindo-se de princípios ou "pontos de consciência" que o artista cênico pode utilizar em seu trabalho. O método explora as questões do espaço e tempo por meio de improvisação e composição corporal e vocal" (BOGART et all, 2005, p. 10).

${ }^{5} \mathrm{O}$ treinamento fortalece as relações, desenvolve habilidades e gera uma, oportunidade para continuar a crescer. Os Viewpoints permitem aos atores e colaboradores de praticar criando ficção juntos num trabalho continuo usando as ferramentas de tempo e espaço. Esta prática contínua, matem o fluxo artístico jorrando, criando cenas e permitindo atores e grupos praticarem a língua do palco.
} 


\section{Teatro contemporâneo como instrumento de autonomia}

O indivíduo no decorrer da sua trajetória de vida busca governar-se por leis e vontades próprias, usando da sua inteligência para tal ganho. Tal processo parece tornar-se tortuoso por falta de conhecimento e ferramentas que lhe amparem nesse ganho de autonomia.

O conceito de empowerment vem ganhando força no decorrer deste século como um suporte teórico-prático entre os grupos sociais mais vulneráveis (negros, índios, mulheres, homossexuais, dentre outros) e em instituições privadas e públicas com objetivo de ampliar o sistema decisório até o menor nível dando aos grupos de trabalho o poder e a autonomia de como realizar suas tarefas. Por não se tratar de um termo fechado, sua funcionalidade reside exatamente na mudança de mentalidade a partir da percepção do sujeito das próprias forças, que resulta em um comportamento de autoconfiança. Através desse processo, pessoas renunciam ao estado de tutela, de dependência, de impotência, e transformam-se em sujeitos ativos, que lutam para si, com e para os outros por mais autonomia e autodeterminação, tomando a direção da vida nas próprias mãos (KLEBA, 2009, p. 735).

Em saúde mental o termo é habitualmente usado para definir o aumento do poder e autonomia pessoal e coletiva de indivíduos e grupos sociais nas relações interpessoais e institucionais, principalmente daqueles submetidos a relações de opressão, dominação e discriminação social (VASCONCELOS, 2003), sua função máxima é de gerar expectativas de reabilitação em indivíduos e grupos acometidos de algum transtorno mental, e reinserção dos mesmos no meio social. Por se tratar de um termo especifico para tratamento do sofrimento psíquico, podendo incluir também não só aqueles em situações emergenciais e de risco, mas também os sofrimentos psíquicos acarretados pelo cotidiano, é adaptável para trabalho com grupos que tem o anseio de empoderar-se de relações institucionais tirânicas e de difícil inserção e manejo, tanto nas hierarquias sociais (família, igreja, circulo social, etc.) como as hierarquias trabalhistas e educacionais, onde, por exemplo, no ultimo caso, o processo burocrático difere, em sua funcionalidade, com toda uma metodologia de ensinoaprendizagem do corpo docente de uma instituição, visto que "a universidade ajuda a sociedade na busca de encontrar os instrumentos intelectuais que, dando ao homem consciência de suas necessidades, lhe possibilitam escolher meios de superação das estruturas que o oprimem" (LUCKESI, 1991. p. 43). 
Trabalhando com alguns conceitos-chave do empowerment, como o Cuidado de $\mathrm{Si}^{6}$ e a Ajuda Mútua ${ }^{7}$, e utilizando das técnicas teatrais contemporâneas para trabalho do ator e construção de cena, a partir das necessidades do grupo, é possível desenvolver excelentes resultados do indivíduo e suas vontades próprias, conduzindo-o de forma dinâmica rumo a [re]construir-se de valores morais, sociais e [re]pensar seu papel/função dentro da sua realidade social.

O Teatro do Oprimido é comumente usado para trabalhar com grupos que, de alguma forma, sofreram opressão por alguma instituição, seja ela em qual instancia for, como negros excluídos de sociedades majoritariamente brancas, operários sem poder de decisão em suas respectivas instituições de trabalho, mulheres excluídas de sua autonomia na comunidade e/ou no seio familiar, comunidades com anseio de participação no poder decisório das políticas de seus municípios, dentre outros. "O espaço estético é um espelho de aumento que revela comportamentos dissimulados, inconscientes ou ocultos" (BOAL, 2013. p. 27), logo, o teatro do oprimido é um espaço de debate e experimentação estética e prática do social, levando para a cena construções suscitadas entre as conversações dos participantes e facilitador, dialogando com o status quo e suas possibilidades de mudança.

A partir destas perspectivas de trabalho, a prática de fortalecimentos de todos os elementos morais, intelectuais, sociais e filosóficos envolvidos neste trabalho, dar-se-á em forma de vivência artística, ou seja, uma forma de trabalho que busca utilizar de metodologias artísticas no desenvolvimento de habilidades profissionais e pessoais, dentro de um contexto, utilizando-se de textos, diálogos e atividades práticas.

\section{A/r/tografia como processo investigativo}

O método positivista de investigação científica considera que tanto o processo como os resultados da pesquisa convêm que sejam matematizados, isto é, reduzidos a termos numéricos, em defesa de maior objetividade e confiabilidade. Mas a noção de investigação e a forma de abordá-las foram se ampliando e estendendo para além da limitada noção de pesquisa científica, como, por exemplo, a Investigação Baseada em Arte (IBA), que seria um

...tipo de pesquisa de orientação qualitativa que utiliza procedimentos artísticos (literários, visuais e performativos) para dar conta de práticas de experiência em que tantos os diferentes sujeitos (investigador, leitor, colaborador) como as

\footnotetext{
6 “... iniciativa e a vontade individual de cada pessoa [...] de elaboração de suas vivencias pessoais difíceis e de aumento do poder contratual em suas relações interpessoais e sociais”. (VASCONCELOS, P. 27)

7 “... troca de vivências, experiências, de ajuda emocional e discussão das diferentes estratégias para lidar com os problemas comuns..." (VASCONCELOS, P. 28)
} 
interpretações sobre suas experiências desvelam aspectos que não fazem visíveis em outros tipos de pesquisa (HERNÁNDEZ, 2013. p. 44).

Sendo assim, algumas pesquisas não se enquadram no modelo positivista, pois não visam quantificar o indivíduo, apenas se concentrar nos seus relatos biográficos e centralidades narrativas como processo qualitativo de coleta e análise de dados, visando fazer um diagnóstico fundamentado dos fatos para se alcançar uma mudança intencional no comportamento dos indivíduos ou de uma fração da população e propor a ação saneadora ao problema enfrentado (CHIZZOTTI, 2016. p. 79)

A a/r/tografia é uma das muitas formas de Investigação Baseada em Arte, uma Pesquisa Viva ${ }^{8}$, um encontro constituído através de compreensões, experiências e representações artísticas (IRWIN, 2013. p. 28), ou seja, através de um método artístico (literatura, música, performatividade) a pesquisa a/r/tográfica amplia a interpretação da perspectiva de realidade que se apresenta e possibilita novas resoluções do problema suscitado.

O uso da performatividade como aporte na metodologia do trabalho científico, vem sido explorada por estudantes, mestres e doutores desde a década de 90 como instrumento de pesquisa. Exemplos como estes podem ser encontrados nos artigos de Pagès, 2010 ${ }^{9}$, Fels, 1999, Linds, 2002 e Michaels, $2000^{10}$, nestes exemplos a pesquisa performativa enfatiza forma, função e ação e a pesquisa cria um espaço especializado (aberto e dialógico) que é simultaneamente assegurado para a investigação e expressão (FINLEY apud SINNER et all, 2013. p. 106).

\section{Instrumentos de metodologia e autonomia}

Para dar conta do todo proposto, baseei-me em pesquisas e vivencias de trabalho solo e coletivas, dentro de autarquias e grupos artísticos com estéticas variadas. Logo, a primeira coisa a ser trabalhada é a autonomia física, antes de qualquer trabalho corporal prático, é necessário fazer com que o participante sinta e perceba seu corpo. Com processos de alongamento aliados aos exercícios de yoga, e dinâmicas de expressão e consciência corporal, podemos alcançar esta autonomia física, estimular, paulatinamente, para as práticas performativas e incitar esta metodologia no cotidiano do participante.

\footnotetext{
8 "É uma Pesquisa Viva porque se trata de estar atento à vida ao longo do tempo, relacionando o que pode não parecer estar relacionado, sabendo que sempre haverá ligações a serem exploradas”. (IRWIN. 2013. P. 29)

${ }^{9}$ Ver referências bibliográficas.

${ }^{10}$ Encontrados no Quadro 1 - Resumo das teses e dissertações baseadas em artes defendidas na Faculdade de Educação da UBC em 1994, no artigo de SINNER et all, 2013. P. 116-119.
} 
A partir das proposições do teatro negativo, é possível descobrir o que atrapalha na respiração, no movimento e, o mais importante de todos, no contato humano. Que resistências existem? Como podem ser eliminadas? (GROTOWSKI, 1992. p. 180). Agregando esses questionamentos com a pratica de alongamentos e exercícios físicos, o empoderamento do corpo e seus movimentos é percebido e trabalhado, e logo dá-se base prática para que cada participante elabore sua própria rotina de exercícios, percebendo seu corpo não mais como uma máquina de reprodução automática, mas como objeto essencial de transformação do próprio cotidiano.

Ao longo dos anos em trabalho com iniciantes nas artes dramáticas, interessados e/ou curiosos, os exercícios de clown deram base significativas para que os mesmos pudessem executar outras atividades com mais maleabilidade e entrega, pois não havia mais a preocupação com o "ridículo" da ação, a própria situação de representar já é, em si, "ridícula", entendendo o adjetivo não pelo seu valor pejorativo, mas como uma forma cômica/clownesca de re/a/presentar uma situação, sem juízos de valor moral e/ou estético. A técnica de clown foi desenvolvida como um elemento e uma técnica auxiliar ao trabalho do ator (WUO, 2009. p. 58) aliada ao empoderamento físico, as dinâmicas de clown propostas, entrarão como suporte para execução das atividades futuras. Indicadas tanto no decorrer do processo de pesquisa, quanto no decorrer da vida acadêmica e social, pois o clown nada mais que é que o nosso "ridículo" exposto, sem máscaras nem escudo, apenas existindo em sua essência pura.

Para exercitar o lado criativo da mente e do corpo, o trabalho com Viewpoints entra como metodologia de percepção e criação do espaço-tempo. Os pontos usados nesta metodologia serão: o Espaço (capacidade perceptiva para ver e sentir as relações físicas que se estabelecem), a Forma (capacidade de ver e sentir a forma física), Tempo (habilidade de perceber e experimentar a duração), História (capacidade perceptiva de ver e entender sistemas lógicos como um arranjo de informações) e Vocais (habilidade de exprimir sentido usando o tom, dinâmica, velocidade, timbre e forma). Exercícios como composição de cenas em duplas, as arraias e a composição de cena coletiva serão bastante usadas nesta etapa.

Durante as aulas serão lidos e debatidos alguns textos contemporâneos do teatro do absurdo, como forma de exercitar a oralidade, imaginação, raciocínio, dentre outros. Textos como Esperando Godot de Samuel Becket, A Cantora Careca de Eugene Ionesco, O PingPong de Arthur Adamov, aliados as vivencias de cada participante, levantaremos questões suscitadas nos textos e a esmiuçaremos para que sua interpretação não fique apenas nas palavras do autor e sua subjetividade, mas que cada participante seja estimulado a interpretar as entrelinhas com a sua realidade e estipularmos uma terceira via, que seria um consenso 
entre os participantes, para que democraticamente executemos as futuras dinâmicas baseadas nas questões levantadas.

\section{Conclusão}

Acredito que com as referências encontradas e indicadas, disponibilizei arranjos complementares as artes dramáticas e relações sociais, e a possibilidade, quase, infinita do uso do teatro como instrumento prático e político de sujeitos com anseio por transform[ação], e sua capacidade de transmutar realidades utópicas em realidades possíveis.

Ao construir, com esmero, cada etapa desta metodologia para criação e validação do conceito criado, me permiti observar atentamente e deixar ser atingido a realidade que me cercava, bem como as apresentações orais dos colegas de classe, além de apresentações de mestres, doutores dentre outros, em eventos dentro fora da instituição de ensino, e isso me fez crescer em análise e pesquisa, me possibilitando visões múltiplas desta, e uma possível ampliação para outros campos, como o ganho de autonomia em comunidades periféricas, organizações não-governamentais que trabalhem com minorias, empresas privadas que que tem o anseio de empoderar-se de relações institucionais tirânicas e de difícil inserção e manejo.

\section{REFERÊNCIAS}

BOGART, Anne. LANDAU, Tina. The Viewpoints Book: a practical guide to viewpoints and composition. New York. Theatre Communications Group, 2005.

BOAL, Augusto Teatro do oprimido e outras poéticas políticas. São Paulo. Cosac Naify. 2013.

BURNIER, Luís Otávio. A Arte de Ator: da técnica a representação. $2^{\text {a }}$ Ed. Campinas. Unicamp. 2009. 312p.

CHIZZOTTI, Antonio. Pesquisa Qualitativa em Ciências Humanas e Sociais. Petrópolis/RJ. Vozes. 2006.

DEMO, Pedro. Introdução a metodologia da ciência. São Paulo. Atlas. 1985. . Saber Pensar. São Paulo. Cortez: Instituto Paulo Freire. 2002.

GOFFMAN, Erving. A representação do eu na vida cotidiana. $10^{\mathrm{a}}$ Ed. São Paulo. Petrópolis. Vozes. 1985.

GROTOWSKI, Jerzy. Em busca de um teatro pobre. $4^{a}$ Ed. Rio de Janeiro: Civilização Brasileira, 1992.

HERNÁNDEZ, Fernando Herández. A pesquisa baseada nas artes: proposta para pensar a pesquisa educativa. Tradução de Tatiana Fernandez. In: DIAS, Belidson e IRWIN, Rita 
(Orgs.). Pesquisa Educacional Baseada em Arte: A/r/tografia. Santa Maria: Editora UFSM, 2013, p 39-62.

IRWIN, Rita L. A/r/tografia. Tradução de Belidson Dias. In: DIAS, Belidson e IRWIN, Rita (Orgs.). Pesquisa Educacional Baseada em Arte: A/r/tografia. Santa Maria: Editora UFSM, 2013, p 27-35.

KLEBA, Maria Elisabeth; WENDAUSEN, Agueda. Empoderamento: processo de fortalecimento dos sujeitos nos espaços de participação social e democratização política. Saude soc. [Periódico na internet] São Paulo, v. 18, n. 4, dez. 2009 . Disponível em <http://www.scielo.br/scielo.php?script=sci_arttext\&pid=S010412902009000400016\&lng=pt\&nrm=iso>. Acesso em 10 fev. 2015.

PAGÈS, Judit Vidiella. Pedagogias de Contacto: Performance y Prácticas de Corporización. In DAMIANO, Gilberto A.; PEREIRA, L. H. P.; OLIVEIRA, Wanderley C. (orgs.) Corporeidade e educação: tecendo sentidos. São Paulo-SP. Cultura Acadêmica. 2010.

LUCKESI, Cipriano. BARRETO, Elói. COSMA, José. BAPTISTA, Naidison. Fazer Universidade: Uma proposta metodológica. 6 ${ }^{\text {a }}$ Ed. São Paulo. Cortez. 1991.

RYNGAERT, Jean-Pierre. Ler o Teatro Contemporâneo. Tradução Andréa Stabel M. da Silva. São Paulo; Martins Fontes. 1998.

SINNER, Anita; LEGGO, Carl; IRWIN, Rita L; GOUZOUASIS, Peter; GRAUER, KIT. Analisando as práticas dos novos acadêmicos: teses que usam metodologias de pesquisa em educação baseada em arte. Tradução de Belidson Dias. . In: DIAS, Belidson e IRWIN, Rita (Orgs.). Pesquisa Educacional Baseada em Arte: A/r/tografia. Santa Maria: Editora UFSM, 2013, p 98-124.

VASCONCELOS, Eduardo Mourão. O poder que brota da dor e da opressão: empowerment, sua história, teorias e estratégias. São Paulo. Paulus. 2003.

WUO, Ana Elvira. A linguagem secreta do clown. Integração [periódico na internet]. 2009. Disponível em: ftp://ftp.usjt.br/pub/revint/57_56. pdf. Acesso em: 06 de Agosto de 2015. 